\title{
Twelve Years of High Frequency Absolute Gravity Measurements at the UK's Space Geodesy Facility: Systematic Signals and Comparison with SLR Heights
}

\author{
Victoria Anne Smith, Graham Appleby, Marek Ziebart, and Jose Rodriguez
}

\begin{abstract}
Absolute gravity measurements taken on a near-weekly basis at a single location is a rarity. Twelve years of data at the UK's Space Geodesy Facility (SGF) provides evidence to show that the application of results from international comparisons of absolute gravimeters should be applied to data and are critical to the interpretation of theSGF gravity time series of data from 2007 to 2019. Though residual biases in the data are seen. The SGF time series comprises near weekly data, with exceptions for manufacturer services and participation in international instrument comparisons. Each data set comprises hourly data taken over 1 day, with between 100 and 200 drops per hour. Environmental modelling indicates that the annual groundwater variation at SGF of some $2 \mathrm{~m}$ influences the gravity data by 3.1 $\mu \mathrm{Gal}$, based upon some measured and estimated soil parameters. The soil parameters were also used in the calculation of the effect of an additional telescope dome, built above the gravity laboratory, and have been shown to be realistic. Sited in close proximity to the long-established satellite laser ranging (SLR) system and the global navigation satellite systems (GNSS) the absolute gravimetry (AG) measurements provide a complimentary geodetic technique, which is non space-based. The SLR-derived height time series provides an independent measurement of vertical motion at the site which may be used to assess the AG results, which are impacted by ground motion as well as mass changes above and below the instruments.
\end{abstract}

\section{Keywords}

Absolute gravimeter - Gravimetry · International Terrestrial Reference Frame (ITRF) • Satellite Laser Ranging (SLR) · Time series

V. A. Smith $(\varangle)$

NERC/BGS Space Geodesy Facility, Herstmonceux Castle,

East Sussex, UK

e-mail: vism@nerc.ac.uk

\section{G. Appleby}

British Geological Survey Honorary Research Associate,

Nottingham, UK

e-mail: gapp@nerc.ac.uk

M. Ziebart

Department of Civil, Environmental and Geomatic Engineering, Faculty of Engineering Science, University College London, London, UK

e-mail: m.ziebart@ucl.ac.uk

\section{Introduction}

Characterisation of key geodetic sites for the improvement of their products is important for the demands of geodesy and the various reference frames which are built upon the data from the worldwide geodetic observatories. The addition of absolute gravity (AG) measurement capabilities at the Space Geodesy Facility (SGF) was prompted by the growing demands of the Global Geodetic Observing System (GGOS)

\footnotetext{
J. Rodriguez

Centro Astronómico de Yebes, Guadalajara, Spain

e-mail: jc.rodriguez@oan.es
} 
and the European Combined Geodetic Network (ECGN). An early goal for the observatory was to determine if the geodetic products from the long established satellite laser ranging (SLR) and GNSS, could be improved through better characterisation of any un-modelled or mis-modelled signals by a non-space based AG technique. Determination of the glacial isostatic rate for the southeast of the UK was an additional long term goal.

In this paper, the results of 12 years of near-weekly AG data are presented. The environmental effects and calculations are briefly discussed. Emphasis is placed on the interpretation of the time series as a whole, where instrumentational inter-comparisons, data offsets and bias offsets are discussed and analysed. Finally, a comparison is made between the AG time series and station heights derived from SLR.

\section{Site Information}

The UK's Space Geodesy Facility is funded by the UK Natural Environment Research Council through the British Geological Survey. It is located in East Sussex, less than $5 \mathrm{~km}$ from the English Channel. The geodetic techniques of SLR, GNSS and absolute gravity measurements form the principle operations at the observatory, though numerous additional sensor data, including sun photometry and automated measurements of groundwater depth, atmospheric visibility, pressure, temperature and humidity, are recorded. The site is compact with each geodetic technique contained within $25 \mathrm{~m}$. An additional GNSS antenna is located around $100 \mathrm{~m}$ distant. The gravimetry laboratory is located SE from the SLR, three meters below ground level as measured at the borehole, in a semi-sunken bunker that has approximately $1.2 \mathrm{~m}$ of soil above it. Unusually for geodetic sites, the subsurface is comprised of clay, with no bedrock beneath within $30 \mathrm{~m}$. The local soil type is known to be Weald clay (British Geological Survey website ${ }^{1}$ ). Absolute gravity measurements have been taken at the observatory since 2006 on a near-weekly basis. The standard measurements comprise of hourly data sets with 100-200 drops per set taken for $25 \mathrm{~h}$ once a week.

\section{$3 \quad$ Hydrology}

The hydrology surrounding the gravity laboratory is slightly complex due both to its semi-sunken nature and the slope on which the SGF sits (Fig. 1). It has been well documented that water movement should be accounted for when analysing gravity data (Makinen and Tattari 1990; Harnisch

${ }^{1}$ http://mapapps.bgs.ac.uk/geologyofbritain/home.html?

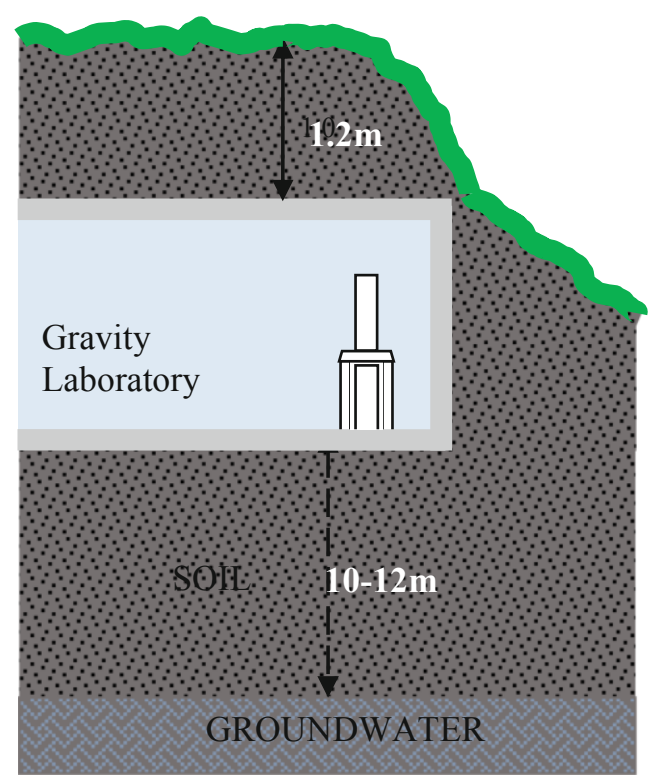

Fig. 1 Schematic to show the semi-sunken nature of the gravity laboratory

and Harnisch 2006) groundwater, soil moisture and rainfall all change the mass around gravimeters and therefore, it should be understood in order to interpret the data correctly. Groundwater data have been recorded at Herstmonceux since the mid 1990s by an automatic data logging system in a borehole, measurements are recorded as depth below ground level. There is currently no capability for soil moisture to be recorded.

However, using estimates made by testing soil samples, approximations of the influence of these hydrologicallyinduced signals on the AG data have been made. The density, porosity and specific yield were needed to estimate the differences between wet and dry soils both above and below the gravimeter. The modified Bouguer plate corrections for soil moisture and ground water are:

$$
\begin{aligned}
& \delta g_{s m}=2 \pi G H \rho_{w} \delta P=4.2 H \delta P \\
& \delta g_{g w}=2 \pi G P \rho_{w} \delta H=4.2 P \delta H
\end{aligned}
$$

Where $\delta g_{s m}$ indicates the effect on gravity given by a change in soil moisture, $\delta g_{g w}$ indicates the effect on gravity given by a change in groundwater depth, $\mathrm{G}$ is the gravitational constant, $\rho_{w}$ is the density of water, $\delta P$ is the change in the water filled pore spaces in the soil and $\delta H$ is effective change in depth to groundwater.

The effect on gravity, due to the variation of water content in the $1.2 \mathrm{~m}$ of soil above the gravimeter, was calculated to be less than $1 \mu \mathrm{Gal}$. The influence on the gravity data due to seasonalvariation in the groundwater height, of between 10 and $12 \mathrm{~m}$ below the gravity laboratory, has been calculated 
Fig. 2 HGO AG time series showing significant events

Fig. 3 Regimes split by event

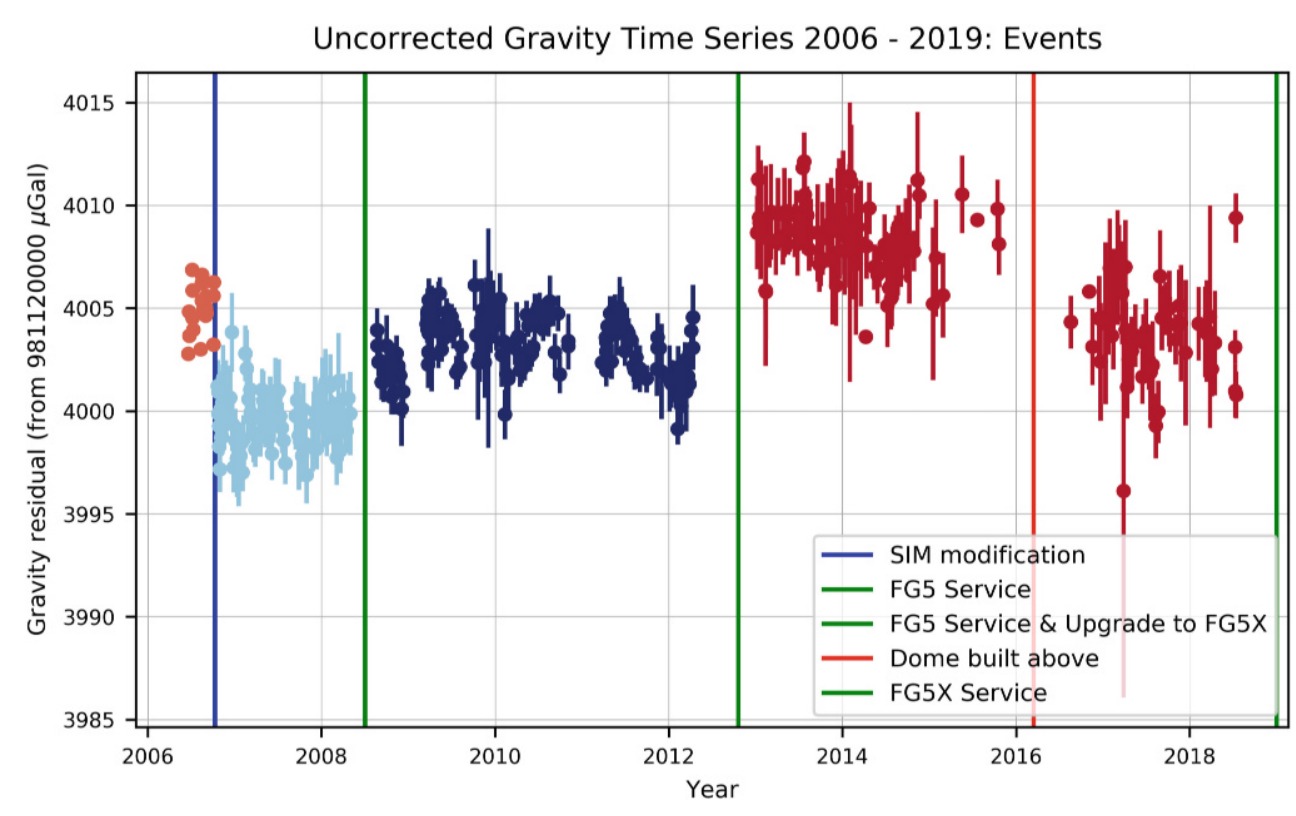

Uncorrected Gravity Time Series 2006 - 2019: Events

Gravity Time Series 2006 - 2019

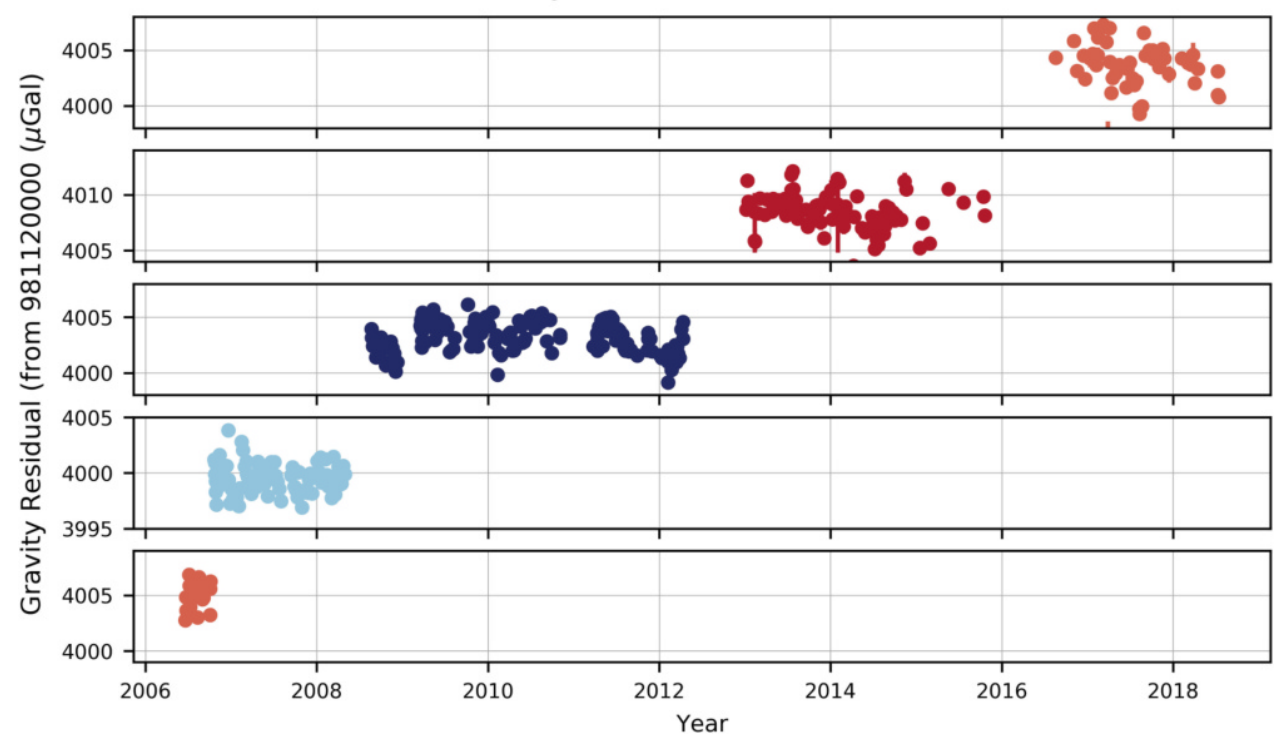

to be $3.1 \mu \mathrm{Gal}$ at maximum. Application of the groundwater correction gives an almost imperceptible change to the appearance of the AG time series. Full details of these calculations can be found in the PhD thesis by Smith (2018). ${ }^{2}$

\section{$4 \quad$ Interpretation of the Time Series}

The weekly gravity data as presented in Fig. 2 clearly contain some interesting features. However, these features become of particular significance when important events such as changes to the instrumentation or environment are

\footnotetext{
${ }^{2}$ Available from the British Library or UCL Discovery website.
}

highlighted, as shown in Fig. 2. These events appear to cause clear offsets in the time series of AG data. If the data are split into slices, dictated by each event, then each resulting 'regime' of data, as shown in Fig. 3, can be analysed and the differences between them can be studied.

It is interesting to note that the data in each regime falls within a $10 \mu \mathrm{Gal}$ range but are offset in mean value. Also, the standard deviation about the mean of each regime is similar: $1.17,1.31,1.39,1.56$ and $2.28 \mu \mathrm{Gal}$.

It should also be noted that the precision of the AG measurements has been decreasing for several years, which is thought to be driven by the environment, as comparison data has not indicated any problem with the instrument. 
Fig. 4 Comparison corrected time series

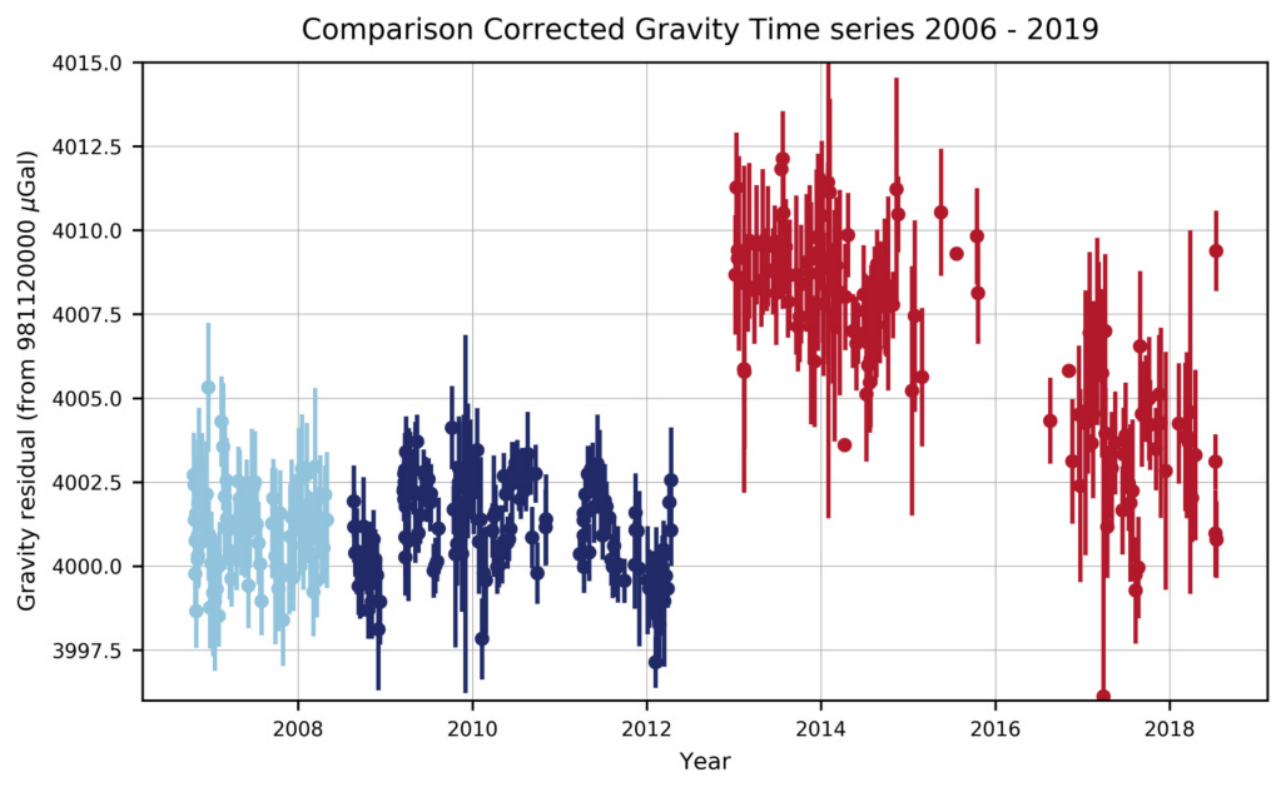

If the data are to be interpreted as a whole, it is clear that the offset changes, coincident with instrumental visits to the manufacturers, need to be accounted for. Since the measurement of gravity is dependent on instrumentation, as well as spatial and temporal variables, no estimation of the accuracy of the instruments is possible. To quantify results of absolute gravimeters the best solution is to obtain relative offsets between instruments during international gravimeter comparisons (Francis et al. 2013). Relative offset values obtained from comparison results were obtained three times during this time series for the FG5 used (FG5-229). The comparisons results for 2007 and 2015 gave offset results for the SGF instrument of $+1.5 \pm 0.8$ and $0.08 \pm 0.8 \mu \mathrm{Gal}$ respectively (Francis and van Dam 2010; Pálinkáš et al. 2017). A basic mini-comparison was carried out in 2012, courtesy of O. Francis, at the Walferdange Underground Laboratory, with another FG5 (FG5-216) which itself was found to have an offset of $+1.8 \pm 3.1 \mu \mathrm{Gal}$ during the international comparison of 2011 (Francis et al. 2013). Since FG5-229 was found to be in very close agreement $(0.2 \pm 1 \mu \mathrm{Gal})$ with FG5-216, the offset of +1.8 has been used for FG5229. Unfortunately, since there is no supporting comparison for the early data, before the SIM (system interface module, through which the majority of signals are passed and contains control electronics) repair in 2006, the data from the first regime shown in Figs. 2 and 3 have been discounted from further analysis at this time.

The offset corrections from the comparisons have been applied and the resulting time series is shown in Fig. 4. The data from 2007 to 2013 have been significantly smoothed and now appears to give consistent data. However, there are significant discontinuities remaining thereafter.
The offset in the data from 2016 onwards is of known origin; a small telescope dome was built above the gravity laboratory. An approximate calculation of mass change, based upon volume of clay extracted from above the gravity laboratory and the addition of concrete and brick, implies an offset in the gravity measurement of $3.6 \mu \mathrm{Gal}$. This is in reasonable agreement with the observed mean offset as discussed below. However, the data from 2013 are concerning. They have a large residual offset after the comparison results are applied. We have no evidence to support any local environment changes that could have accounted for this level of change over the 3 months that the instrument was away at the manufacturers. Although heavily researched, this bias remains of unknown origin.

Several methods could be employed to determine the biases in the 2013-2016 and 2016-2019 data sets. However, using the simplest method, calculating the mean values of each regime, proves to be an acceptable method in this case, since the difference between the mean values of each regime compares favourably with both the offsets obtained from the 2007 and 2011 comparisons and the estimated effect of mass changes due to the additional telescope dome. The comparisons in question gave a total offset of $3.5 \mu \mathrm{Gal}$, while the difference between the mean values is $3.6 \mu \mathrm{Gal}$. The calculated change due to the additional dome built above the laboratory, based upon soil samples, indicated an expected offset of $3.6 \mu \mathrm{Gal}$, whereas the difference between the mean values gives $4.8 \mu \mathrm{Gal}$. It should have noted that the dome calculations did not account for the additional masses from the telescope, telescope mount, pier or dome, which would all increase the expected offset. Furthermore, in earlier work, the magnitude of the bias in 2013 was taken to be $7.3 \mu \mathrm{Gal}$ 
Fig. 5 Time Series corrected by comparison offsets and mean differences

Fig. 6 Campaign simulation, uncorrected for bias, dome or comparisons

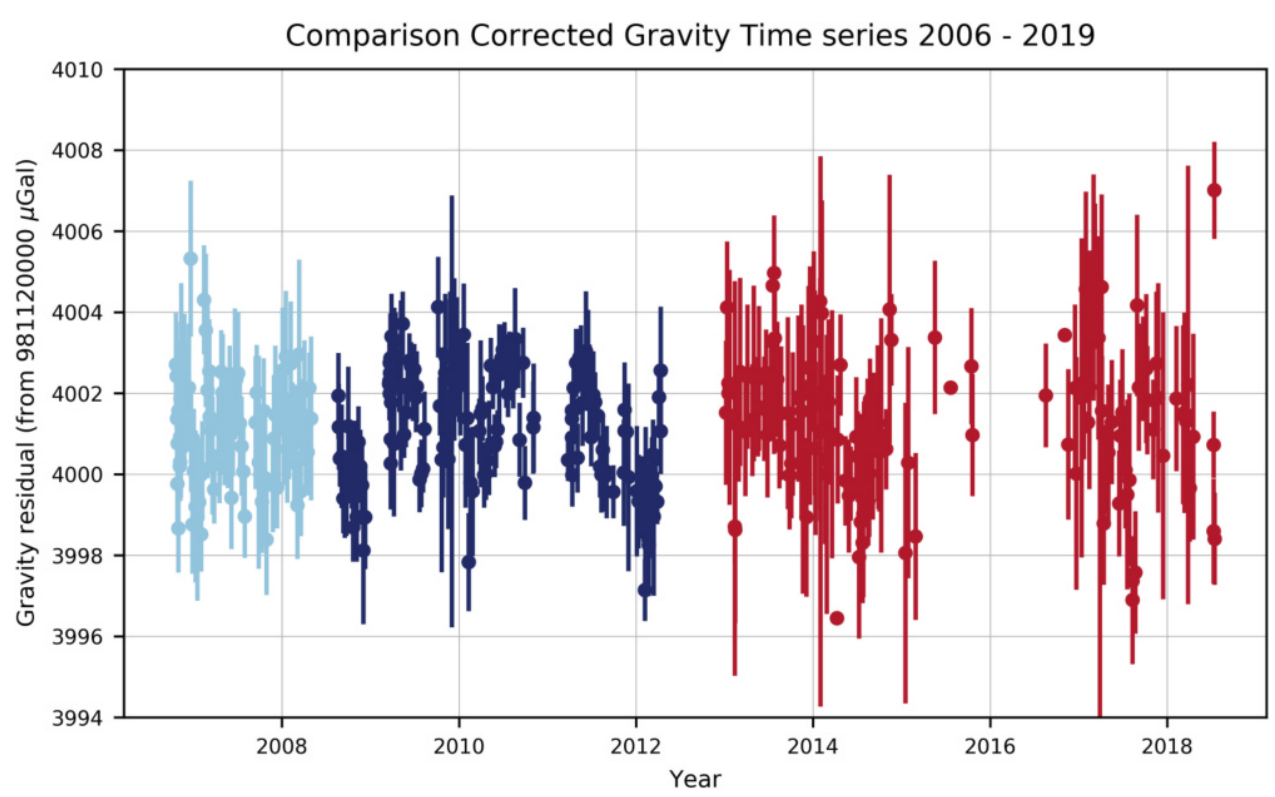

Simulation of 'campaign' single project measurement 2006 - 2019: Uncorrected

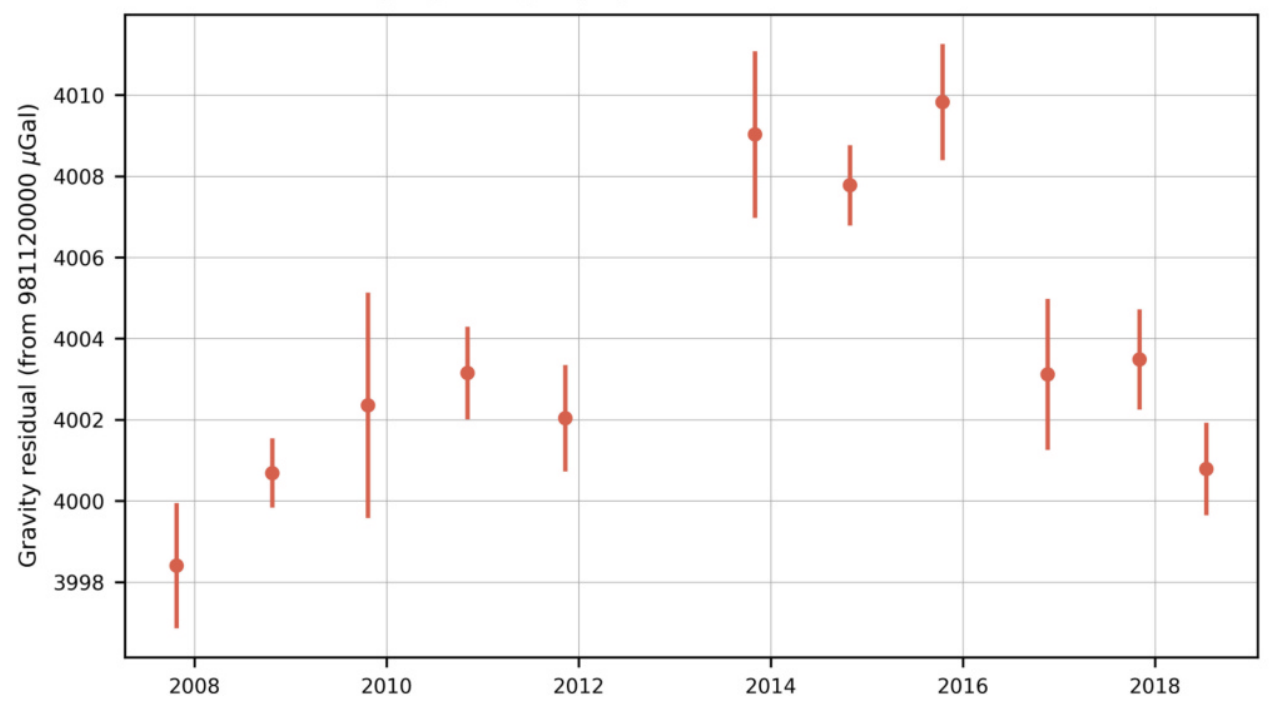

obtained by 'best-fit', whilst the difference between the mean values gives an offset close to this of $7.2 \mu \mathrm{Gal}$. When these offsets are applied, in addition to the offsets provided by comparisons of instruments, the results are shown in Fig. 5.

\section{$5 \quad$ Campaign Simulation}

To emulate low frequency FG5 data a 'campaign style' simulation was applied to the SGF time series; by taking one data point per year from the full SGF time series. Project data, comprising $25 \mathrm{~h}$ of data, were selected around the same epoch each year and plotted in Fig. 6. Interpretation of these results could be critical for a country-wide project: it could be tempting to apply an offset for the 2013 to 2017 data and estimate a glacial isostatic adjustment (GIA) rate from the residual. Such an interpretation would be critically flawed given our understanding of events in the whole SGF time series.

Bias and comparison corrected results for this campaign simulation are given in Fig. 7.

\subsection{AG vs SLR Heights}

The SGF is an International Laser Ranging Service (ILRS) Analysis Centre (AC) and is responsible for computing reference frame solutions that are subsequently made freely 
Fig. 7 Campaign simulation data corrected for bias, dome and comparisons

Fig. 8 AG data, converted to heights, plotted in red, with SLR derived station height changes plotted in green
Simulation of 'campaign' single project measurement 2006 - 2019: Corrected

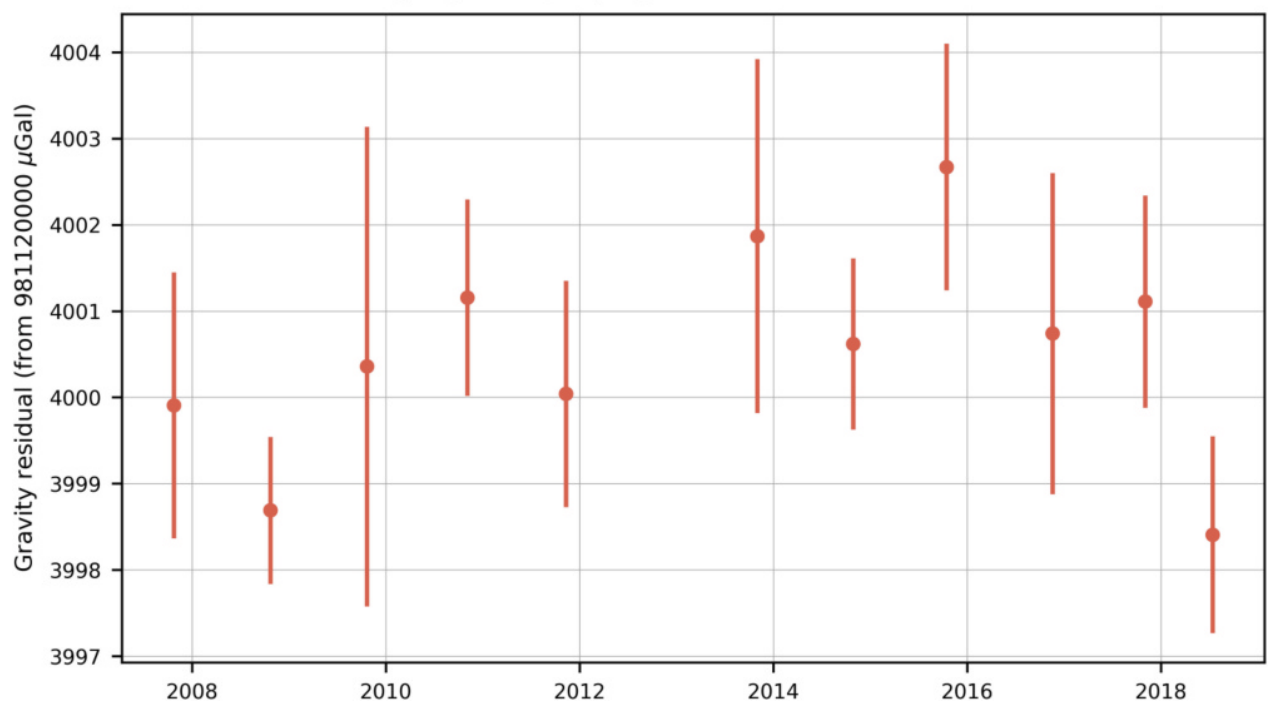

SLR and AG Vertical Displacements: 2007 -2019

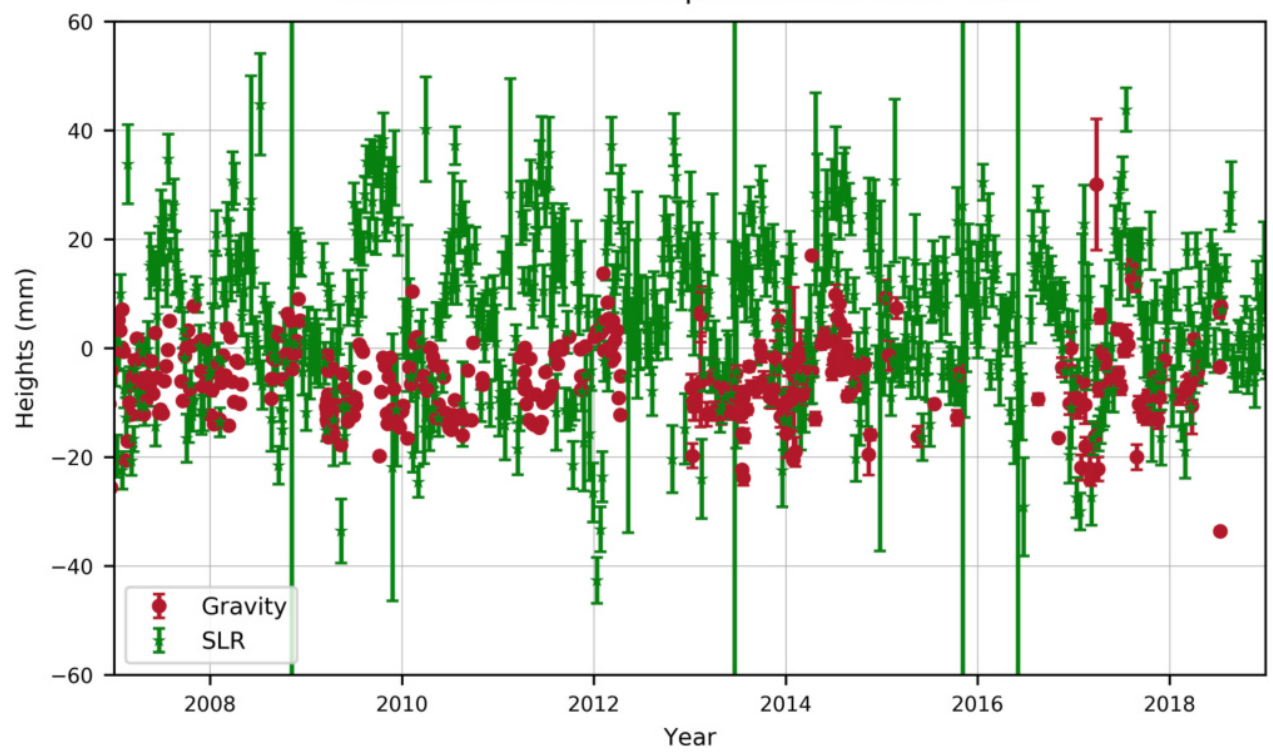

available to the community via ILRS Data Centres. ${ }^{3}$ The SGF AC contributed multi-year solutions towards the realisation of the International Terrestrial Reference Frame (e.g., ITRF2014, (Altamimi et al. 2016)) using global SLR measurements to the LAGEOS and Etalon satellites. In addition, research carried out by the AC, (Appleby et al. 2016; Rodríguez et al. 2019) after the work that contributed to ITRF2014, has identified subtle systematic effects in the range measurements at each station of the ILRS network that impact in particular the derived station heights at the few $\mathrm{mm}$ to $10 \mathrm{~mm}$ level. As a consequence of this work, new solutions for station coordinates that take account of

\footnotetext{
${ }^{3}$ https://ilrs.cddis.eosdis.nasa.gov/data_and_products/data_centers/
} index.html. these small systematics have been computed and may be considered close-to bias free. The resulting weekly-averaged heights of the Herstmonceux site thus provide a reference height series against which to measure the stability and potential systematics in the AG gravity observations; the AG measurements will be impacted by height changes, as tracked by the SLR solutions, as well as mass changes above and below the AG instrument, primarily hydrological changes as discussed in Sect. 3. Therefore, the data from the two techniques are not expected to match precisely. The SLR and AG time series (converted to height by the use of a multiplication factor of $-5 \mathrm{~mm} / \mu \mathrm{Gal}$ (Teferle 2009)) are shown in Fig. 8, where the data has been aligned in the vertical axis by matching the first data point of both the AG and SLR data. It is very interesting and promising to note that the AG series provides a smoother representation of the 
height variation of the site than is determined by the SLR time series.

\section{Conclusion}

The high frequency, near weekly, AG data from SGF show clear evidence of the importance of testing the instruments after they have been serviced and after changes to the instrument have been carried out by the manufacturer. The implementation of the comparison results from international meetings is seen to be critical, though not the complete story for the bias offset seen in 2013. It is alarming that this bias coincides with the major instrument change of the upgrade of the FG5 to an FG5X. The results indicate that instrument comparisons should be carried out as often as is practical for all users of FG5s.

SLR-derived site height variations are used to validate the concept of applying the corrections made to the AG time series that results from inter-comparisons, bias estimation and new dome building. SGF is currently testing an additional site in the UK with an aim to be able to offer a minicomparison site for the community. scale: estimation of systematic errors in LAGEOS observations 1993-2014. J Geod 90(12):1371-1388, 1-18. https://doi.org/10. 1007/s00190-016-0929-2

Francis OE, van Dam T (2010) Results of the European comparison of absolute gravimeters in Walferdange (Luxembourg) of November 2007. In: Gravity, geoid and earth observation, International Association of Geodesy Symposia. Springer, Berlin, pp 31-35

Francis OE et al (2013) The Euopean comparison of absolute gravimeters 2011 (ECAG-2011) in Walferdange, Luxembourg: results and recommendations. Metrologia 50:257-268

Harnisch G, Harnisch M (2006) Hydrological influences in long gravimetric data series. J Geodyn 41:276-287

Makinen JT, Tattari S (1990) Subsurface water and gravity. In: Proceedings of 11th Internatinal symposia on earth tides 1989. Schweizerbart'sche Verlagsbuchhandlung, Stuttgart

Pálinkáš V et al (2017) Regional comparison of absolute gravimeters, EURAMET.M.G-K2 key comparison. Metrologia 54:07012

Rodríguez J, Appleby GM, Otsubo T (2019) Upgraded modelling for the determination of Centre of mass corrections of geodetic SLR satellites. Impact on key parameters of the terrestrial reference frame. J Geod 93(12):2553-2568. https://doi.org/10.1007/s00190019-01315-0

Smith VA (2018) Extracting geodetically useful information from absolute Gravimetry at a fundamental Geodetic Station. University College London, London

Teferle FN (2009) Crustal motions in Great Britain: evidence from continuous GPS, absolute gravity and Holocene Sea level data. Geophys J Int 178(1):23-46

\section{References}

Altamimi Z et al (2016) ITRF2014: a new release of the international terrestrial reference frame modeling nonlinear station motions. J Geophys Res Solid Earth 121:6109-6131

Appleby G et al (2016) Assessment of the accuracy of global geodetic satellite laser rangning observations and estimated impact on ITRF

Open Access This chapter is licensed under the terms of the Creative Commons Attribution 4.0 International License (http://creativecommons.org/ licenses/by/4.0/), which permits use, sharing, adaptation, distribution and reproduction in any medium or format, as long as you give appropriate credit to the original author(s) and the source, provide a link to the Creative Commons license and indicate if changes were made.

The images or other third party material in this chapter are included in the chapter's Creative Commons license, unless indicated otherwise in a credit line to the material. If material is not included in the chapter's Creative Commons license and your intended use is not permitted by statutory regulation or exceeds the permitted use, you will need to obtain permission directly from the copyright holder.

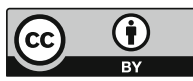

